\title{
Comprehensive review of the evidence regarding the effectiveness of community-based primary health care in improving maternal, neonatal and child health: 5. equity effects for neonates and children
}

\author{
Meike Schleiff ${ }^{1}$, Richard \\ Kumapley², Paul A Freeman ${ }^{3,4}$, \\ Sundeep Gupta ${ }^{5}$, Bahie M \\ Rassekh$^{6}$, Henry B Perry ${ }^{1}$ \\ ${ }^{1}$ Department of International Health, Johns \\ Hopkins Bloomberg School of Public Health, \\ Baltimore, Maryland, USA \\ ${ }^{2}$ UNICEF, New York, New York, USA \\ ${ }^{3}$ Independent consultant, Seattle, Washington, \\ USA \\ ${ }^{4}$ Department of Global Health, University of \\ Washington, Seattle, Washington, USA \\ ${ }^{5}$ Medical epidemiologist, Lusaka, Zambia \\ ${ }^{6}$ The World Bank, Washington, DC, USA
}

Background The degree to which investments in health programs improve the health of the most disadvantaged segments of the population-where utilization of health services and health status is often the worst - is a growing concern throughout the world. Therefore, questions about the degree to which community-based primary health care (CBPHC) can or actually does improve utilization of health services and the health status of the most disadvantaged children in a population is an important one.

Methods Using a database containing information about the assessment of 548 interventions, projects or programs (referred to collectively as projects) that used CBPHC to improve child health, we extracted evidence related to equity from a sub-set of 42 projects, identified through a multi-step process, that included an equity analysis. We organized our findings conceptually around a logical framework matrix.

Results Our analysis indicates that these CBPHC projects, all of which implemented child health interventions, achieved equitable effects. The vast majority ( $87 \%$ ) of the 82 equity measurements carried out and reported for these 42 projects demonstrated "pro-equitable" or "equitable" effects, meaning that the project's equity indicator(s) improved to the same degree or more in the disadvantaged segments of the project population as in the more advantaged segments. Most (78\%) of the all the measured equity effects were "pro-equitable," meaning that the equity criterion improved more in the most disadvantaged segment of the project population than in the other segments of the population.

Conclusions Based on the observation that CBPHC projects commonly provide services that are readily accessible to the entire project population and that even often reach down to all households, such projects are inherently likely to be more equitable than projects that strengthen services only at facilities, where utilization diminishes greatly with one's distance away. The decentralization of services and attention to and tracking of metrics across all phases of project implementation with attention to the underserved, as can be done in CBPHC projects, are important for reducing inequities in countries with a high burden of child mortality. Strengthening CBPHC is a necessary strategy for reducing inequities in child health and for achieving universal coverage of essential services for children.

\section{Correspondence to:}

Henry Perry

Room E8537

Johns Hopkins Bloomberg School of Public

Health

615 North Wolfe St.

Baltimore, MD 21205

USA

hperry2@jhu.edu 
Martin Luther King, Jr., in a speech in 1966 to the Medical Committee for Human Rights, proclaimed, "Of all the forms of inequality, injustice in health care is the most shocking and inhumane" [1]. Between countries and within countries, inequalities in health status are by and large considered inequitable because they can be greatly reduced or even eliminated through stronger health programs. In spite of marked improvements in health programming and health status around the world, inequities are not diminishing as much as many countries and stakeholders had hoped [2-4]. Particularly since the 1990s, measuring and working to reduce inequities — with a goal ultimately to reach zero — has been on the global health agenda from global and national policy-makers to major donors [3-6].

Issues of health inequities for maternal, neonatal and child health (MNCH) in low- and middle-income countries (LMICs) are being increasingly studied. Some progress is being made in a number of areas such as the use of insecticide-treated net (ITN) usage to prevent malaria, exclusive breastfeeding, and immunization coverage [7]. Further, approaches for reaching underserved populations are receiving increasing attention in order to achieve the Millennium Development Goals (MDGs) [4] and the newly established Sustainable Development Goals (SDGs) [8]. At the global level, a recent declaration [9] brought together national public health associations from around the world to focus and mobilize action for achieving health equity by building evidence, addressing the social determinants of health (SDH), and incorporating equity components into health policies. Nonetheless, a great deal of learning and work remains to be done in order to accelerate reductions in health inequities.

Recent evidence from tracking of the "Countdown to 2015" [7-12], when the MDGs were supposed to be achieved, shows that population coverage of key interventions provided by health services is improving for the poorest quintiles of national populations at a rate faster than that for the wealthiest quintiles. However, the poorest quintiles are still facing markedly lower levels of coverage than the wealthier quintiles in most Countdown countries (the 74 countries with $97 \%$ of the world's child and maternal deaths, ie, the greatest burden of maternal, neonatal and child mortality). Even though some measures of health inequities are slowly improving, substantial challenges remain for how to accelerate this progress $[3,4]$. The gaps are wider for interventions that require access to fixed health facilities or repeat contacts with a health provider (such as a skilled birth attendant) than for interventions that can be delivered through outreach strategies at the community level [5]. The countries that have made rapid progress in coverage are those that effectively reached the poorest families [5]. This is despite starting with great inequities. For example, in Cambodia and Sierra Leone in 2000 the richest had much higher coverage than the rest, but by 2014 this difference had disappeared [13].

The terminology around inequities, inequalities, and disparities has been the topic of debate over the past decades [14]. We will use the following interpretations of the terms in the context of this article. Disparities and inequalities (often used interchangeably) refer to differences among socially or geographically defined groups in health service utilization, in risk factors for unfavorable health outcomes, in levels of morbidity or mortality (collectively referred to here as health status) - essentially encompassing the entirety of epidemiological inquiry [14]. Inequity, however, "does not refer generically to all differences in health, but focuses specifically on the sub-set of differences that are 'avoidable, unfair, and unjust" [14]. In practice, studies of inequities in health often focus on the degree to which marginalized and disadvantaged groups within geographically defined populations have less access to health care resources and have lower utilization of health care services.

Such differences stem from characteristics such as educational level, income (or wealth), race, child's gender, geographic location, religion, or other characteristics of a social group that persistently produce social barriers that can lead to health outcomes that are different from those of other social groups. Beyond the semantics, Braveman argues that how we define and use these terms has important and relevant implications for policy and practice, and these definitions can determine the measures used to determine progress and even the flow of funding for different interventions [14]. Alternately, Taylor suggested a definition of equity as the, "distribution of benefits according to demonstrated need [health status] rather than on the basis of political or socioeconomic privilege" [15]. He focused on equity of the health status of populations rather than more proximal indicators of health system inputs or health service utilization.

From a public health perspective, it is important to examine the equity of both health program implementation and health outcomes among different socially and geographically defined sub-populations. Overall improvements in the health of a population can occur without every sub-group benefiting equally $[7,16,17]$.

The equity effects of MNCH programs have undergone perhaps the greatest scrutiny of any global health program. One of the recent drivers for this scrutiny was the challenge of meeting the MDGs by 2015 and 
accelerating progress in countries that were lagging behind $[11,12,18]$. Analysts observed that, within many countries, inequities in child mortality were widening in spite of overall downward trends in child mortality [19].

Analyses have been conducted using Demographic and Health Survey (DHS) and Multiple Indicator Survey (MICS) data from MDG Countdown Countries regarding the population coverage of key maternal and child health interventions by income quintiles to assess equity in coverage [4,5]. Results showed trends toward increased equity in coverage of key interventions. Some of the most equitably implemented interventions are those that can fairly easily be implemented within communities, such as ITN utilization, promotion of exclusive breastfeeding (EBF), and community-based provision of immunizations $[7,10,20,21]$. At the same time, widening inequities were observed among different population subgroups for interventions that require facility-based, higher-level personnel such as skilled birth attendants and treatment of serious childhood illness [22]. These interventions often require a more developed health system including education and support of skilled personnel, more advanced equipment, referral processes, and other support structures in order to be effective, and thus tend to be less evenly distributed among population groups $[7,10]$.

While equity issues are often considered from a national or large-population perspective, they may exist at the local level as well. In one long-standing comprehensive health program in Haiti serving 148000 people with a strong community-based service delivery system, the utilization of health facilities, the population coverage of key interventions, and the health outcomes of sub-groups of the program area differed markedly among those living in the more isolated mountain communities compared to those is nearer valley communities. This reality persisted despite great efforts being made to extend both primary health care services and access to CHWs equally throughout the program area [23].

This article makes two contributions to the equity literature. First, it consolidates for the first time the evidence regarding the equity effects of CBPHC programs on child health and organizes them around a logical framework. Second, this article reviews the various dimensions of equity that child health programs need to consider, including wealth (or household assets), maternal education, child's sex, geographic location, and gender of the child's caregiver and identifies dimensions where limited analysis has been conducted.

\section{METHODS}

\section{Data sources}

We used a recently assembled database containing assessments of 548 studies, projects or programs (referred to collectively as projects) that used CBPHC (defined in the initial paper in this series [24]) to improve neonatal or child health (henceforth referred to as child health) and to document these improvements. In brief, CBPHC was considered to be one or more interventions carried out in the community outside of a health facility. The additional presence of one or more facility-based interventions did not disqualify the project from inclusion.

The database and its assembly have been described elsewhere in this series [10]. In short, peer-reviewed documents, reports and books assessing the impact of one or more CBPHC interventions on child health (coverage of a key child survival indicator, nutritional status, serious morbidity, or mortality) in LMIC settings, among children in a geographically defined population, were selected. Two independent data extraction reviews were carried out and followed by an independent consolidated summative review. Data from the latter review were transferred to electronic database.

From this database, we identified a sub-set of 42 projects that had carried out an equity analysis as part of their assessment using the process described in the following section.

\section{Article review and inclusion process}

Using the PRISMA guidelines for systematic reviews on health equity $[25,26]$, we identified a sub-set of 138 articles in which equity was mentioned in one or more of the following fields in the CBPHC project database: 1) the title of the article, 2) the documentation of the process of the intervention, 3) part of the data analysis strategy, or 4) in the notes provided by the reviewers of the assessment for inclusion in the 


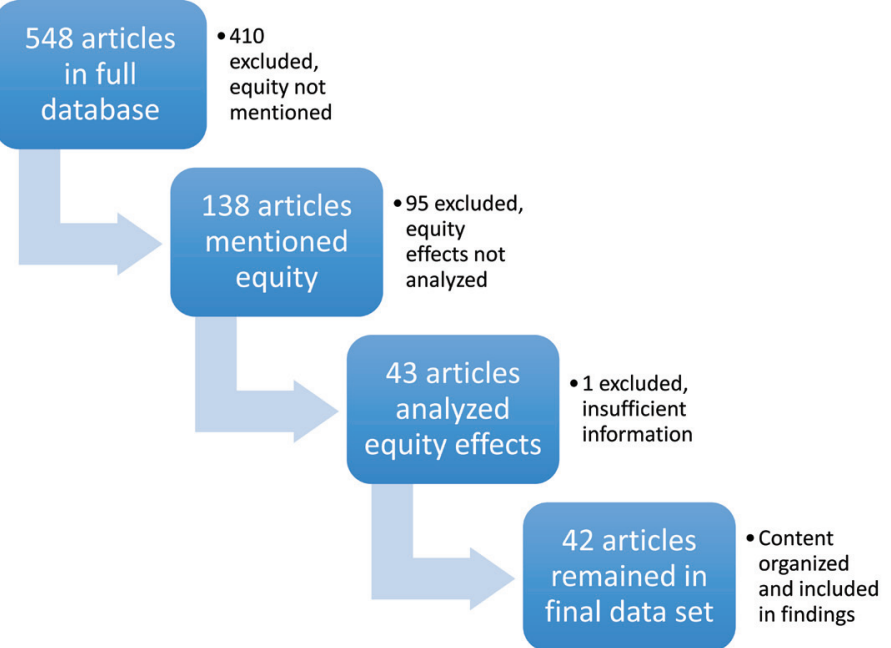

Figure 1. Overview of sequence of article review and inclusion/ exclusion criteria. systematic review. We carefully reviewed this sub-set of equity-relevant assessments and excluded assessments in which equity was not actually analyzed across population subgroups. After this focusing phase, we were left with 43 projects to examine further.

Two of the authors (MS and RK) separately reviewed each of these 43 projects and extracted additional data on how equity was defined in each assessment, what data sources were utilized for assessment of equity effects, and what the outcome on equity actually was. The metrics from each project being assessed were stratified into log-frame categories (input, process, output, outcome, impact). One article was excluded from the analysis because it did not provide sufficient information on how equity was analyzed, leaving 42 articles in the final data set (Figure 1). Aside from the availability of adequate information on equity analysis in each article, the quality of the study was not assessed.

\section{Criteria for equity analysis}

In order to identify the diverse criteria utilized among the studies to analyze equity, we created open-text responses as we reviewed each assessment, and then categorized them into common themes as we identified commonalities among the identified categories. We summarize the categories below and provide examples for some of the less-common categories. In our literature review, we identified a USAID report [27] on incorporating equity into project designs for $\mathrm{MNCH}$ that offered guidance on identifying disadvantaged groups that should be considered in implementing equitable $\mathrm{MNCH}$ projects. The USAID report referred to these groups by the acronym PROGRESS (Place of residence, $\underline{\text { Race, }}$ Occupation, $\underline{\text { Gender, }}$ Religion, Education, and Socioeconomic Status) [28]. This typology provided guidance for the kinds of characteristics to look for and how to organize the findings from the reports we analyzed.

\section{Categorization of equity outcomes}

We created three categories of outcomes for the various equity indicators used by the assessments included in our analysis (pro-equitable, equitable, and inequitable, as defined in Box 1). We categorized indicators as pro-equitable if findings favored underserved populations and were statistically significant or, if tests of statistical significance were not carried out, the study authors described their results as having practical significance. Indicators with findings that were similar for underserved groups as for the other groups were categorized as equitable. Indicators with findings that showed unfavorable outcomes for underserved populations were categorized as inequitable.

These categories helped us to differentiate between several important equity outcomes -namely when disadvantaged sub-groups were benefitting less, equally, or more than other sub-groups. If disadvantaged

Box 1. Definitions

Pro-equity effect: when inputs, processes, and outcomes for disadvantaged groups improved more than for advantaged groups by the end of project implementation.

Equity effect: when inputs, processes, and outcomes for disadvantaged groups improved to the same degree as advantaged groups by the end of project implementation.

Inequity effect: when inputs, processes and outcomes for disadvantaged groups improve less than for advantaged groups by the end of project implementation.

Dimension of equity: A characteristic — such as household income, level of maternal education, or whether a child lives in an urban or rural areas - that can be used to compare population groups through an equity lens and determine whether different sub-groups of the population receive different levels of services or achieve different outcomes.

Equity indicator: An indicator of child health—such as rates of home visitation for newborns, for example that was analyzed across a dimension of health equity. 
groups were benefitting less, this was an inequitable outcome. When disadvantaged groups were benefitting equally, this was noted as a good sign, though not a fully optimal outcome since disadvantaged groups often need to make additional progress in order to overcome inequities.

\section{Organization of identified metrics for health equity into a logical framework}

Barros et al. [19] offer a framework for analysis of health equity from the standpoint of an individual person's experience with an illness, beginning with the socioeconomic context through exposures to disease, vulnerability to succumbing to disease, and the outcomes and consequences of illness. While this approach helped us think through the various ways that equity can influence child health work, we opted to organize the indicators of health equity used by the assessments included in our analysis by utilizing a different framework of analysis from the standpoint of project implementation: beginning with inputs and processes, and then moving to outputs, outcomes, and impacts [29] to track at what point in project implementation equity dimensions were assessed. This made it possible to identify gaps and opportunities from a project planning and implementation perspective. Figure 2 below provides a graphic representation of the conceptual flow of this log-frame matrix from one phase to another.

We created a matrix for each phase of the logical framework and, for each of the included indicators, tabulated the equity effects of each project. For each cell of the matrix, we described the content of the project and drew conclusions from the available evidence.

Each assessment was further analyzed to determine the criteria used to define equity, the type of data used to assess equity, and the scope of the assessment as well as the types of indicators measured in the assessment. The definition of equity was not pre-determined, and the definitions of equity used in the assessments were categorized after the list of equity indicators used in the projects had been reviewed. This was done to avoid missing any relevant equity indicators that might not have fit into a pre-determined definition of equity.

The type of data used to assess equity was defined as primary or secondary. The term primary data refers to data collected by the project, while the term secondary data refers to data which were gathered by another entity. Secondary data included those obtained from DHS and MICS data sets. Finally, each indicator was further classified as to whether it was referring to a project input, process, output, outcome or impact.

Table 1. Geographical location of reports containing equity analyses

\begin{tabular}{lc} 
Geggraphical hegion & Number of Studies \\
\hline Africa & 19 \\
\hline Southeast Asia & 14 \\
\hline Americas & 8 \\
\hline Western Pacific & 1 \\
\hline Total & 42 \\
\hline
\end{tabular}

\section{RESULTS}

\section{Location of included projects}

The assessments included in our analysis were for projects from various regions of the world (Table 1). One of the studies included data from 28 African countries, and another had data from four African countries. All other studies focused on one country or a smaller sub-population within that country as shown in Table 1.
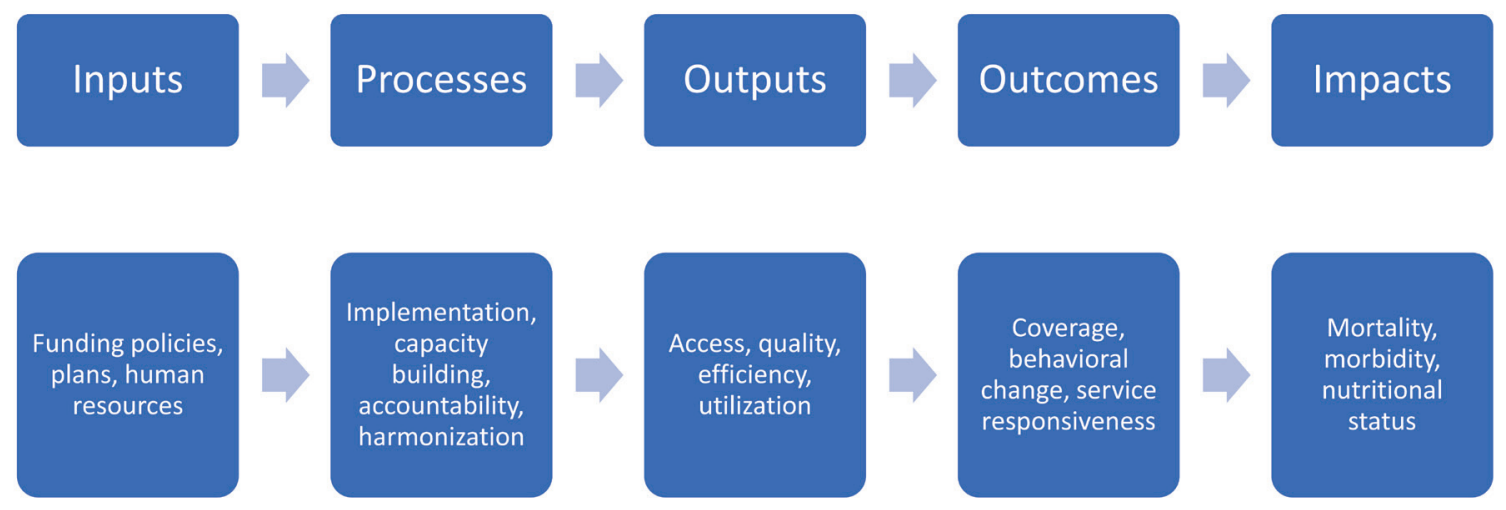

Figure 2. Generalized log frame for health projects. 


\section{Kinds of data used in the assessments}

The data utilized in 37 of the 42 projects including equity analyses collected specifically by the project within the project's geographic area. However, five analyses exclusively utilized data from DHS and MICS surveys, and two utilized both project-level data collected for assessment of the project and also publicly available national data.

\section{Criteria through which equity effects were assessed}

Across the 42 projects included in our analysis, 82 equity indicators - for example coverage of prenatal home visits analyzed across household income categories (Callaghan-Koru, 2013; reference [S15] in Online Supplementary Document) - were identified. Equity was measured by comparing changes in health program characteristics or health status over time for more disadvantaged groups with changes in the identical indicators for more advantaged groups. Table 2 summarizes the criteria by which disadvantaged groups were distinguished from more advantaged groups.

We grouped several equity indicators under a category we refer to as socioeconomic status (SES). These included income categories, maternal education, and household characteristics. By far, the most common indicator for assessing equity was a measure of wealth, often based on household income, household assets, household size, or maternal earnings. Other SES equity indicators included in the analysis were agricultural production by heads of household and specific assets present in the household such as a working toilet, running water, or a refuse collection system. Other SES criteria included the ethnic group of the family, religion, marital status of child's parents, occupation of the parents, and demographic characteristics such as maternal age. These equity indicators aligned well with those identified by the USAID PROGRESS report (shown in the right-hand column of Table 2); the only PROGRESS category that was not identified in our analysis was religion [27].

\section{Assessments of equity of inputs}

After careful analysis and discussion among co-authors and colleagues, we determined that no projects that we included in our data set explicitly analyzed or reported inputs from an equity perspective. The dearth of input-related efforts in project design, implementation, and evaluation is concerning and is noted as an area where further work is needed.

\section{Assessments of equity of processes}

A number of the assessments included in our review measured process indicators through an equity lens, as shown in Table 3 (references in Tables 3-6, are prefixed with an S and appear in Online Supplementary Document). Two-thirds (10/13) of the measurements of equity involving process indicators concerned whether the household had received a home visit from a health worker or had contact with the health system. Eleven out of 13 of the measurements yielded a pro-equitable result, and the remaining two yielded an equitable result. Thus, for the process indicators in the assessments selected for analysis, equity had been achieved in all cases and a pro-equity result is observed in almost all. The findings for

Table 2. Equity indicators used in the assessments included in the analysis

\begin{tabular}{|c|c|c|}
\hline EQUITY GRITERION & NuMBER OF ASSESSMENTS IN WHICH THE INDICATOR WAS USED* & CoMPARABIE USAID PROGRESS IndicatoRE \\
\hline \multicolumn{3}{|l|}{ Socioeconomic status (SES): } \\
\hline Household income categories & 45 & Wealth \\
\hline Household assets (production, other assets such as savings) & 5 & Wealth \\
\hline Maternal education & 9 & Gender \\
\hline Social standing (ethnicity, caste, religion, parent marital status) & 8 & Ethnicity \\
\hline Parent occupation & 1 & Wealth \\
\hline \multicolumn{3}{|l|}{ Other: } \\
\hline Geographic location of residence (urban vs rural) & 24 & Geography \\
\hline Child's sex & 3 & Gender \\
\hline Nutritional status & 4 & Wealth \\
\hline Maternal age & 2 & Age \\
\hline Country-level Human Development Index (HDI) & 1 & Wealth \\
\hline
\end{tabular}

*The column total is 82 since many of the assessments in our review included more than one equity indicator. 
Table 3. Assessments of equity effects of CBPHC projects using process indicators*

\begin{tabular}{|c|c|c|c|}
\hline Process INDICATOR & EqUITY CRITERION & Outcome & Reference \\
\hline Postnatal home visit & Household income & Equitable & Callaghan-Koru 2013 [S15] \\
\hline Home visit during pregnancy & Household income & Equitable & Callaghan-Koru 2013 [S15] \\
\hline Azythromycin distribution to entire communities for trachoma & Household assets & Pro-equitable & Cumberland 2008 [S19] \\
\hline CHW visit to caregivers within the past year & Urban vs rural & Pro-equitable & Litrell 2013 [S25] \\
\hline Caregivers report of CHWs working in community & Urban vs rural & Pro-equitable & Litrell 2013 [S25] \\
\hline Prenatal home visit & Household income & Pro-equitable & Baqui 2008 [S8] \\
\hline Number of home visits & Urban vs rural & Pro-equitable & Perry 2006 [S35] \\
\hline Antenatal home visit & Household income & Pro-equitable & Baqui 2008 [S8] \\
\hline At least one home visit during pregnancy & Household income & Pro-equitable & Callaghan-Koru 2013 [S15] \\
\hline Two or more home visits during pregnancy & Household income & Pro-equitable & Callaghan-Koru 2013 [S15] \\
\hline Home visits to support breastfeeding & Household income, maternal education & Pro-equitable & Coutinho 2005 [S17] \\
\hline Child ill and CHW called to come to the home & Household income & Pro-equitable & Siekmans 2013 [S38] \\
\hline At least one ANC visit in home & Household income & Pro-equitable & Nonyane 2015 [S32] \\
\hline
\end{tabular}

* References which are prefixed with an S appear in Appendix S1 of the online supplementary document.

this portion of the log frame consistently support the equitable nature of home visiting practices, a central feature of many CBPHC projects, as also discussed in the in this supplement that directly address the effectiveness of CBPHC in improving MNCH [30-32]. Many of these home visits either implicitly or explicitly included promotion and support of breastfeeding, which has also been noted in the literature as an intervention that can be supported equitably through community-based approaches with multiple benefits to $\mathrm{MNCH}$.

\section{Assessments of equity of outputs}

The assessments of equity using output indicators are listed in Table 4. Two-thirds (4/6) of the six equity assessments using output indicators among the projects selected for our analysis concerned the utilization of specific services or the expected immediate output of an intervention. Half (3/6) of these equity assessments used household income as the equity criterion. The number of assessments is too small to make major generalizations from, but the indicators demonstrating a pro-equity effect in the output category focus on access to health services (either in a facility or in the home). Indicators that demonstrated an inequitable effect were both from the same study and related to the hygienic practices across several equity dimensions.

\section{Assessments of equity of outcomes}

Table 5 below lists the equity assessments carried out using outcome indicators. Many relate to knowledge and behavior change related to breastfeeding or to the population coverage level of an intervention. Of the 35 measurement carried out, only 14\% (5/35) yielded an inequitable result; 11\% (4/35) yielded an equitable result, and the rest (74\%) yielded a pro-equitable result. Inequitable indicators included several interventions requiring significant equipment or knowledge such as vaccine coverage and antenatal and delivery care. Some indicators — such as ITN coverage, availability, and use — showed mixed results across different studies, with some having equitable results across household income categories or urban and rural settings and others not. Equitable and pro-equitable programs commonly focused on equitable behaviors such as breastfeeding and newborn and child health practices that can be implemented in the home without complex or expensive supplies or knowledge.

Table 4. Assessments of equity effects of CBPHC projects using output indicators*

\begin{tabular}{llll} 
OutPUt InDICATOR & EnUIT CRIIERION & OutCOME & REFERENCE \\
Food hygiene score in relation to cleanliness score & Household income & Inequitable & Ahmed 1993 [S1] \\
\hline Food hygiene score in relation to diarrhea prevalence & Maternal education, nutritional status & Inequitable & Ahmed 1993 [S1] \\
\hline Utilization of ambulatory care facility & Urban vs rural & Pro-equitable & Perry 2006 [S35] \\
\hline Number of hospital admissions & Urban vs rural & Pro-equitable & Perry 2006 [S35] \\
\hline Child with fever treated within 24 h & Household income & Pro-equitable & Siekmans 2013 [S38] \\
\hline Essential newborn practices performed & Household income & Pro-equitable & Baqui 2008 [S8] \\
\hline
\end{tabular}

* References which are prefixed with an S appear in Appendix S1 of the online supplementary document. 
Table 5. Assessments of equity effects of CBPHC projects using outcome indicators*

\begin{tabular}{|c|c|c|c|}
\hline OUTCOME INDICATOR & EquITY CRITERION & Outcome & Reference \\
\hline Understanding of overall cleanliness & Maternal education & Inequitable & Ahmed 1993 [S1] \\
\hline Coverage of antenatal and delivery care & Household income & Inequitable & Bryce 2008 [S14] \\
\hline EPI immunization coverage & Household income & Inequitable & Webster 2005 [S42] \\
\hline ITN coverage & Household income & Inequitable & Webster 2005 [S42] \\
\hline Coverage of any type of bed net (ITN or other) & Household income & Inequitable & Webster 2005 [S42] \\
\hline Health service coverage & Child's sex & Equitable & Bryce 2008 [S14] \\
\hline Nothing applied to umbilical cord by mother after birth & Household income & Equitable & Nonyane 2015 [S32] \\
\hline Child with diarrhea treated with ORS or zinc & Household income & Equitable & Littrell 2013 [S25] \\
\hline Awareness of support group in community & Household income & Equitable & Callaghan-Koru 2013 [S15] \\
\hline Exclusive breastfeeding & Urban vs rural & Pro-equitable & Crookston 2000 [S18] \\
\hline Exclusive breastfeeding from birth to $6 \mathrm{~m}$ & Household income & Pro-equitable & Coutinho 2005 [S17] \\
\hline Breastfeeding initiation within first hour of life & Urban vs rural & Pro-equitable & Crookston $2000[\mathrm{~S} 17]$ \\
\hline Breastfeeding initiation within first hour of life & Household income & Pro-equitable & Nonyane 2015 [S32] \\
\hline Knowledge of family planning methods & Urban vs rural & Pro-equitable & Debpuur 2002 [S20] \\
\hline Knowledge and use of family planning & Maternal education, social standing & Pro-equitable & Awooner-Williams 2004 [S5] \\
\hline Recognition of at least 3 danger signs in newborns & Household income & Pro-equitable & Nonyane 2015 [S32] \\
\hline $\begin{array}{l}\text { Child with fever treated with artemether-lumefantrine } \\
\text { within } 48 \text { hours }\end{array}$ & Household income & Pro-equitable & Siekmans 2013 [S38] \\
\hline Acute respiratory infection treatment rate & Household income & Pro-equitable & Mercer 2004 [S28] \\
\hline Any bed net available & Household income & Pro-equitable & Skarbinski 2007 [S39] \\
\hline Measles vaccination rate & Household income & Pro-equitable & Mercer 2004 [S28] \\
\hline Immunization coverage & Household income & Pro-equitable & Bawah 2006 [S10] \\
\hline ITN in home & Household income & Pro-equitable & Skarbinski 2007 [S39] \\
\hline ITN coverage & Urban vs rural & Pro-equitable & Grabowsky 2005 [S23] \\
\hline ITN coverage & Household income & Pro-equitable & Grabowsky 2005 [S23] \\
\hline ITN coverage & Household income & Pro-equitable & Noor 2007 [S33] \\
\hline Immediate drying & Household income & Pro-equitable & Nonyane 2015 [S32] \\
\hline Postnatal care coverage & $\begin{array}{l}\text { Maternal education, household income, social } \\
\text { standing, household assets }\end{array}$ & Pro-equitable & Awooner-Williams 2004 [S5] \\
\hline Children sleeping under ITNs & Household income & Pro-equitable & Noor 2007 [S33] \\
\hline Attended delivery & $\begin{array}{l}\text { Maternal education, household income, social } \\
\text { standing, household assets }\end{array}$ & Pro-equitable & Awooner-Williams 2004 [S5] \\
\hline Antenatal care & $\begin{array}{l}\text { Maternal education, household income, social } \\
\text { standing, household assets }\end{array}$ & Pro-equitable & Awooner-Williams 2004 [S5] \\
\hline Antenatal care coverage & Household income & Pro-equitable & Baqui 2008 [S8] \\
\hline
\end{tabular}

* References which are prefixed with an S appear in Appendix S1 of the online supplementary document.

\section{Assessments of equity of health impact}

Finally, Table 6 lists the assessments of health equity that were carried out for health impact-related indicators (nutritional status, morbidity or mortality). Of the 28 projects that included an equity assessment of health impact, 20 were based on a measure of mortality; four were based on a measure of morbidity and four on a measure of nutritional status. Overall, 23 of the 28 assessments demonstrated pro-equitable results and one yielded an equitable result. Only four of the 28 yielded an inequitable result.

\section{Overall summary of equity effects using household wealth as the equity criterion}

We have summarized all the findings reported above in which household income was the equity criterion (Table 7). Overall, 75\% (33/44) of these effects were pro-equitable outcome, 9\% were equitable outcomes, and only 16\% (7/44) yielded an inequitable effect.

\section{Overall summary of all equity effects}

Finally, we have summarized equity effects in Table 8. Overall, 78\% (64/82) of the equity assessments carried out yielded a pro-equitable outcome; 9\% (7/82) yielded an equitable outcomes, and only 13\% (11/82) yielded an inequitable outcome.

While in-depth analysis of the impact of packages of interventions was not the focus of this paper (another paper in this series [33] addresses this strategy in general - not limited to equity), we reviewed which projects constituted a single intervention vs a package of interventions. Of the 42 projects, 11 
Table 6. Assessments of equity of CBPHC projects using impact indicators*

\begin{tabular}{|c|c|c|c|}
\hline IMPACT INDICATOR & EquITY CRIIERION & Outcome & RefERence \\
\hline Neonatal morality rate & Household income & Inequitable & Razzaque 2007 [S36] \\
\hline Under-5 mortality rate & Urban vs rural & Inequitable & Bryce 2008 [S14] \\
\hline Under-5 mortality rate & Household income & Inequitable & Razzaque 2007 [S36] \\
\hline Child (age 6-59 months) mortality rate & Social standing, child's sex & Inequitable & Bishai 2005 [S12] \\
\hline Tetanus neonatorum mortality rate & Urban vs rural & Equitable & Newell 1966 [S31] \\
\hline Diarrhea prevalence in children 0-36 months of age & Urban vs rural & Pro-equitable & Barreto 2007 [S9] \\
\hline Diarrhea prevalence in children 0-18 months of age & Nutritional status & Pro-equitable & Ahmed 1993 [S1] \\
\hline Diarrhea prevalence in children 0-36 months of age & Urban vs rural & Pro-equitable & Barreto 2007 [S9] \\
\hline Undernutrition prevalence & Nutritional status & Pro-equitable & Mustaphi 2005 [S30] \\
\hline Child nutrition status (qualitative data) & Nutritional status & Pro-equitable & McNelly 1998 [S29] \\
\hline Perinatal mortality rate & Urban vs rural & Pro-equitable & Bang 2005 [S7] \\
\hline Perinatal mortality rate & Urban vs rural & Pro-equitable & Bang 1999 [S6] \\
\hline Neonatal mortality rate & Urban vs rural & Pro-equitable & ASHA-India 2008 [S4] \\
\hline Neonatal mortality rate & Urban vs rural & Pro-equitable & Bang 1999 [S6] \\
\hline Infant mortality rate & Maternal education, child's sex & Pro-equitable & Fegan 2007 [S21] \\
\hline Infant mortality rate & Urban vs rural & Pro-equitable & Asha-India 2008 [S4] \\
\hline Infant mortality rate & Social standing, parental occupation & Pro-equitable & Bang 1999 [S6] \\
\hline Infant mortality rate & Household income & Pro-equitable & Bhuiya 2002 [S11] \\
\hline Infant mortality rate & Household assets, maternal education & Pro-equitable & Bang 2005 [S7] \\
\hline Infant mortality rate & Human development index & Pro-equitable & Aquino 2009 [S2] \\
\hline Infant mortality rate & Household income & Pro-equitable & Mercer 2004 [S28] \\
\hline Infant, $1-4$ years, and under -5 mortality rates & Household income & Pro-equitable & Mercer 2004 [S28] \\
\hline Under -5 mortality rate & Household income & Pro-equitable & Sepulveda 2006 [S37] \\
\hline Under -5 mortality rate & Urban vs rural, household income & Pro-equitable & Asha-India 2008 [S4] \\
\hline Under-5 mortality rate & Urban vs rural & Pro-equitable & Perry 2006 [S35] \\
\hline Under-5 mortality rate & Household income & Pro-equitable & Bryce 2008 [S14] \\
\hline Under -5 mortality rate & Urban vs rural & Pro-equitable & Asha-India 2008 [S4] \\
\hline
\end{tabular}

* References which are prefixed with an S appear in Appendix S1 of the online supplementary document.

Table 7. Summary of assessments of equity using socio-economic status or household wealth quintile as the equity criterion

\begin{tabular}{lcccc} 
TyPE Of InDICATOR & \multicolumn{5}{c}{ EFFECT ON EQUTIY } \\
& Inequitable & Equitable & Pro-equitable & Total \\
Input & 0 & 0 & 0 & 0 \\
\hline Process & 0 & 2 & 7 & 9 \\
\hline Output & 1 & 0 & 2 & 3 \\
\hline Outcome & 4 & 2 & 18 & 24 \\
\hline Impact & 2 & 0 & 6 & 8 \\
\hline Total & 7 & 4 & 33 & 44 \\
\hline
\end{tabular}

Table 8. Summary of all assessments of equity

\begin{tabular}{lcccc} 
Type of INDICATOR & \multicolumn{5}{c}{ EFFEct On EOUITY } \\
& Inequitable & Equitable & Pro-equitable & Total \\
Input & 0 & 0 & 0 & 0 \\
\hline Process & 0 & 2 & 11 & 13 \\
\hline Output & 2 & 0 & 4 & 6 \\
\hline Outcome & 5 & 4 & 26 & 35 \\
\hline Impact & 4 & 1 & 23 & 28 \\
\hline Total & 11 & 7 & 64 & 82 \\
\hline
\end{tabular}

(26\%) included a single intervention while eight (19\%) included 2 interventions, and 23 (55\%) of projects had a package of three or more services. We could not identify any clear patterns between the number of interventions and how equitable the findings were; the only clear pattern was that, in general, all interventions and equity dimensions within any particularly project tended to be the same in terms of equity outcomes (eg, all of the findings for Ahmed 1993 were inequitable).

Of the 42 projects that conducted an equity analysis, we also reviewed which ones analyzed more one or more dimensions of equity. 27 (64\%) included an analysis for only one dimension of equity while nine (21\%) included two dimensions of equity, and only six (14\%) included three or more dimensions of equity. We also did not identify any obvious patterns among the small groups of projects in each of these categories. Household income as part of SES was by far the most common dimension of equity, and was utilized across all of these categories followed closely by comparing urban vs rural populations. The projects with inequitable findings included a number of SES analyses and also child gender and an urban vs rural comparison. 


\section{DISCUSSION}

We have carried out an equity analysis of the projects in our review that contained evidence regarding the equity effects of CBPHC in improving child health. Out of the 546 assessments related to child health in our data set, 42 measured equity effects. Of the 82 measurements of equity effects in these 42 projects, $87 \%$ of these measurements indicated that the equity effect was either equitable (in which the disadvantage group benefitted to the same degree as the more advantaged group) or pro-equitable (in which the disadvantaged group benefitted more). Of the 42 articles in our review, 15 of them (36\%) measured two or more equity dimensions and 31 articles (74\%) measured equity across two or more interventions. These findings provide strong evidence of the capacity of $\mathrm{CPBHC}$ to reduce inequities in the delivery of child health services and in child health outcomes. Thus, these findings are consistent with the assertion that $\mathrm{CBPHC}$ has the potential to reduce inequities in child health in low-income settings where health facilities alone would be highly unlikely to reduce existing inequities since, in fact, it is well-known that health facility utilization in low-income settings is highly inequitable, as explained further below.

The counter-argument to this assertion is that expansion of the number of facilities and improvements in facility-based care will eventually reduce inequities in child health. This may be possible in the very long term, but there is no evidence at present that we are aware of demonstrating that expanding or improving facility-based services as an isolated strategy reduces inequities in the delivery of child health services or in child health status. For the near term, resources will continue to be highly constrained in low-income countries and major geographic [34], social and financial barriers will continue to exist in accessing facility-based care. Therefore, our findings indicate that strong expansion of CBPHC will be required to reduce inequities in child health.

A case example from Brazil of equity effects of CBPHC on improving child health (an article selected from database) serves as an example of the potential pro-equity effects of combining community-based approaches with political will and investment, a national strategy, and a long-term commitment).

Aquino et al., 2008 (reference [S12] in Online Supplementary Document) analyzed the effects of expanding Brazil's Family Health Program (FHP) coverage on infant mortality. They identified that the effect of the FHP program was greatest in terms of decreasing infant mortality in municipalities where infant mortality was highest and the human development index was lowest at the beginning of the study period. The FHP program used a family-centered approach to provide a range of services at the community level, including promotion of breastfeeding, prenatal care, immunizations, and management of diarrhea. The team of health workers, in addition to physicians and nurses as well as oral health professionals, includes CHWs (called Community Health Agents) who visited every home on a monthly basis. This national program has brought Brazil global recognition for its efforts to reduce health inequities for the general population and for children in particular (including inequities of childhood nutritional status). A high level of political will has been necessary in order to implement the scale and depth of this program at the national level.

\section{Explaining the pro-equity effects of community-based primary health care}

Most CBPHC projects are designed to reach every household with health education and information about how to access outreach services (if not to actually provide services including curative care), and outreach services are generally distributed more evenly throughout target populations than facility-based services [35]. Meanwhile, some countries, such as Peru, where great investment in health facilities has taken place-including expansion of community health centers - these efforts have resulted in only very small improvements on equitable utilization of health facilities [36].

Research on the equity of facility utilization in low-income settings is limited; more evidence is available for high-income settings in the Americas, Europe, and Asia. In LMIC settings, health facilities tend to be few and far between, often expensive from the perspective of the poor, and lacking high quality of care, including provision of care that is seen by certain sub-groups as disrespectful [36-38]. Factors such as education level, income, and urban and rural residence play key roles in determining whether someone is more or less likely to seek care at a health facility $[36,37]$. Thus, the effort and resources that patients and their families have to expend to reach a health facility and the uncertain return on that family's investment contributes to low utilization of facility-based services.

The challenge of providing interventions that are often only available in health facilities - or require infrastructure and skills difficult to deploy in communities outside of facilities-is significant as well. A growing literature, including but also going beyond the database used in this study, points to inequitable usage of health facilities in terms of the SES and urban/rural characteristics of users $[23,34,39]$. 
The need for alternative approaches beyond health facilities to achieve equity in and in fact universal coverage for child health are the following: (i) there is an exponential decline in the utilization of health facilities with increasing distance to the health facility (particularly more than $5 \mathrm{~km}$ or 1 hour walk away) [35], and (ii) there is a need for available and affordable public transportation in order to reach health facilities, which is often absent $[33,39]$. What is lacking from the literature are in-depth assessments of equity of health care utilization in terms of distance from a health facility and the effect of distance from health facilities on health status, taking into account also whether community-based care is available to those further away from those facilities.

Strong community-based programs can encourage facility utilization across income strata as can vouchers provided at the community level for specific services, such as antenatal care, to reduce resource barriers to seeking care [40]. The available evidence suggests that CBPHC approaches that reach all households can be more equitable than solely facility-based approaches in terms of coverage of a number of key primary health care services, particularly for vulnerable populations and those who live further away from facilities, who are also usually more disadvantaged in terms of SES [20,41-43].

There are several assessments that directly compare the degree to which CBPHC approaches as opposed to other approaches improve the health of the poorest segment of the project population compared to hat of the better off segment. It makes sense that home-centered, low-resource interventions like breastfeeding promotion and distribution of ITNs would be able to achieve high levels of equity through community-based approaches that often include direct contact with all households [7]. In addition, some of the most promising strategies to improve health equity focus on strengthening community outreach, using CHWs and other lay workers, along with market-driven options such as minimizing or removing user fees and engaging the private sector $[3,44,45]$.

Approaches that make it possible for health workers to reach all households - or at least to reach outreach points that are relatively evenly distributed throughout the project population and close to homes - are inherently more likely to achieve favorable equity effects than facility-based approaches. However, a number of other equity-relevant factors including education, child's sex, ethnicity [46], and urban vs rural contexts [47] cannot be overlooked even within such a strong outreach approach [48]. Health programs in high-mortality, resource-constrained settings lack the capacity to build and operate facilities within easy reach of all who could need to use them - particularly in low-density rural areas. Thus, the decentralization of services and utilization of innovative and proven strategies to support the coverage, quality, and sustainability of those services is essential for achieving health equity.

While the focus of this review is on low-income countries, inequities are also prevalent in higher-income countries as well. Even where more resources are available to address such issues, political will is needed to direct those resources in ways that decrease inequities. An example of progress and success in the arena of health equity is Japan's national policies to provide equitable educational opportunities as well as access to health services without financial barriers [49]. Globally, but particularly in low-income countries, much work remains to be done to make this kind of progress a reality for all populations. In addition to our public health-specific tools and approaches, more comprehensive community development and empowerment frameworks, such as the CHOICE (Capacity-building, uuman rights, Organizational sustainability, Institutional accountability, Contribution, and Enabling environment) framework [50], can help to frame issues of health equity and provide additional entry points for understanding and addressing them. As Victora et al. note [51], just using the data available and recognizing patterns in inequities is not enough; political will and deliberate design and attention to the causes of inequities in programs for child health are necessary to achieve substantial decreases in child mortality among the most disadvantaged sub-populations where the mortality rates are the greatest.

Community-based approaches can reach those furthest from health facilities and can rapidly expand population coverage of key interventions, so these findings are not surprising. These findings stand in stark contrast to the commonly observed finding that utilization of primary health care facilities is inequitable because those in the lower income quintiles are less likely to obtain services there $[52,53]$. To our knowledge, this is the first comprehensive review in the peer-reviewed literature summarizing the equity effects of CBPHC in improving child health.

\section{Limitations of our study}

This study has several limitations that we want to make explicit. First, we have not further disaggregated the articles based on how strong the equity effect is. Second, some of the 42 assessments qualifying for 
our analysis are efficacy studies conducted within community settings in which ideal conditions were present for project implementation. Therefore, we must be careful about generalizing these findings to everyday practice settings. But, that said, it still remains true that strong pro-equity effects are achievable through CBPHC. An analysis of the quality of the data included in the 42 assessments included in our review was beyond the scope of this article. Finally, although a thorough search has been conducted that covers articles published over the past six decades through the end of 2015, we know that there are likely to be more recent articles published since that time that are relevant to this analysis.

We have worked to be clear in our language, conservative in our claims, and yet optimistic about the role of community-based approaches to continue to help bolster health equity for children in disadvantaged populations around the world.

\section{CONCLUSIONS}

Based on the finding that the services provided by CBPHC projects generally reach most or all households and are readily accessible throughout the project population, CBPHC projects are inherently more likely to achieve pro-equity effects than projects that strengthen services only at facilities. The decentralization of service provision and management and the utilization of community-level workers are important for reducing inequities in national programs of countries where the risk of child mortality is high. Equity assessments need to become a standard feature of MNCH programming.

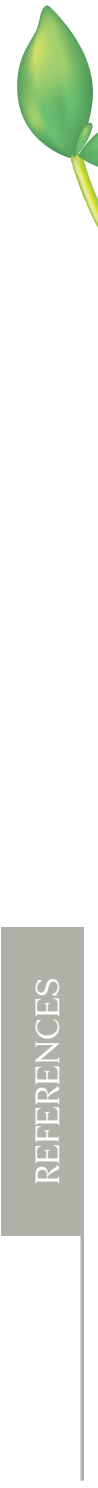

Acknowledgments: We are grateful to Jennifer Winestock Luna for her review of an earlier draft of this manuscript. We are grateful to the following organizations that provided small grants to cover the expenses of this review: UNICEF, the World Bank, the Department of Child and Adolescent Health and Development of the World Health Organization, the CORE Group (Collaboration and Resources for Child Health)/USAID, Future Generations, and the Gates Foundation. We are also grateful to the American Public Health Association and particularly its International Health Section staff, which administered some of these funds. We thank Future Generations for providing office space, administrative support, and salary support to Dr Perry during the initial phase of the review. The World Bank made it possible for one of its consultants, Dr Bahie Rassekh, to participate as a member of the Study Team.

Funding: The following organizations provided funds that were used to conduct the work described in this article: The World Health Organization, UNICEF, the World Bank, the United States Agency for International Development, and the Gates Foundation. The organizations that provided financial support had no role in the execution of the review.

Authorship declaration: MS wrote the first draft. RK and MS conducted the primary analysis of the data. All of the authors participated in the revision of earlier drafts and approved the final draft.

Conflict of interest: All authors have completed the Unified Competing Interest Form at www.icmje.org/coi_disclosure.pdf (available upon request from the corresponding author), and declare no conflict of interest.

1 Moore A. Tracking Down Martin Luther King, Jr.'s Words on Health Care. 2013. Available: http://www.huffingtonpost. com/amanda-moore/martin-luther-king-health-care_b_2506393.html. Accessed: 20 March 2017.

2 Barros AJ, Victora CG. Measuring Coverage in MNCH: determining and interpreting inequalities in coverage of maternal, newborn, and child health interventions. PLoS Med. 2013;10:e1001390. Medline:23667332 doi:10.1371/journal. pmed. 1001390

3 McCollum R, Gomez W, Theobald S, Taegtmeyer M. How equitable are community health worker programmes and which programme features influence equity of community health workers services? A systematic review. BMC Public Health. 2016;16:419. Medline:27207151 doi:10.1186/s12889-016-3043-8

4 Requejo J, Victora C, Bryce J. A Decade of Tracking Progress for Maternal, Newborn, and Child Survival: The 2015 Report. Baltimore, MD: Johns Hopkins University, 2015.

5 Barros AJ, Ronsmans C, Axelson H, Loaiza E, Bertoldi AD, Franca GV, et al. Equity in maternal, newborn, and child health interventions in Countdown to 2015: a retrospective review of survey data from 54 countries. Lancet. 2012;379:1225-33. Medline:22464386 doi:10.1016/S0140-6736(12)60113-5

6 Requejo JH, Bryce J, Barros AJ, Berman P, Bhutta Z, Chopra M, et al. Countdown to 2015 and beyond: fulfilling the health agenda for women and children. Lancet. 2015;385:466-76. Medline:24990815 doi:10.1016/S0140-6736(14)60925-9 
7 Barros AJ, Ronsmans C, Axelson H, Loaiza E, Bertoldi A. Equity in Maternal, Newborn, and Child Health Interventions in Countdown to 2015: A Retrospective Review of Survey Data from 54 Countries. Lancet. 2012;379:1225-33. Medline:22464386 doi:10.1016/S0140-6736(12)60113-5

8 Victora CG, Requejo JH, Barros AJ, Berman P, Bhutta Z, Boerma T, et al. Countdown to 2015: a decade of tracking progress for maternal, newborn, and child survival. Lancet. 2016;387:2049-59. Medline:26477328 doi:10.1016/S01406736(15)00519-X

9 World Federation of Public Health Associations. The Addis Ababa Declaration on Global Health Equity: A Call To Action. 2012. Available: http://www.wfpha.org/tl_files/doc/about/Addis_Declaration.pdf. Accessed: 20 March 2017.

10 Countdown 2008 Equity Analysis Group, Boerma JT, Bryce J, Kinfu Y, Axelson H, Victora CG. Mind The Gap: equity and trends in coverage of maternal, newborn, and child health services in 54 Countdown Countries. Lancet. 2008;371:1259-67. Medline:18406860 doi:10.1016/S0140-6736(08)60560-7

11 Victora CG, Barros A, Axelson H, Bhutta J, Chopra M, Franca G, et al. How changes in coverage affect equity in maternal and child health interventions in 35 Countdown to 2015 countries: an analysis of national surveys. Lancet. 2012;380:1149-56. Medline:22999433 doi:10.1016/S0140-6736(12)61427-5

12 Barros AJ, Ronsmans C, Axelson H, Loaiza E, Bertoldi AD, França GV, et al. Equity in maternal, newborn, and child health interventions in Countdown to 2015: a retrospective review of survey data from 54 countries. Lancet. 2012;379:1225-33. Medline:22464386 doi:10.1016/S0140-6736(12)60113-5

13 UNICEF, World Health Organization. A Decade of Tracking Progress for Maternal, Newborn and Child Survival: The 2015 Report. 2015. Available: http://www.countdown2015mnch.org/documents/2015Report/Countdown_to_2015_final_report.pdf. Accessed: 20 March 2017.

14 Braveman P. Health disparities and health equity: concepts and measurement. Annu Rev Public Health. 2006;27:16794. Medline:16533114 doi:10.1146/annurev.publhealth.27.021405.102103

15 Taylor CE. Surveillance for equity in primary health care: policy implications from international experience. Int J Epidemiol. 1992;21:1043-9. Medline:1483808 doi:10.1093/ije/21.6.1043

16 World Health Organization. Closing the Gap in a Generation: Health Equity Through Action on the Social Determinants of Health. Geneva: World Health Organization; 2008.

17 Hofman K, Blomstedt Y, Addei S, Kalage R, Maredza M, Sankoh O, et al. Addressing research capacity for health equity and the social determinants of health in three African countries: the INTREC Programme. Glob Health Action. 2013;6:19668. doi:10.3402/gha.v6i0.19668

18 Marmot M, Bell R. Social inequalities in health: a proper concern for epidemiology. Ann Epidemiol. 2016;26:238-40. Medline:27084546 doi:10.1016/j.annepidem.2016.02.003

19 Barros F, Victora C, Scherpbier R, Gwatkin D. Health and Nutrition of Children: Equity and Social Determinants. In: Blas E, Kurup AS, editors. Equity, Social Determinants, and Public Health Programmes. Geneva: World Health Organization; 2010.

20 Gilmour S, Shibuya K. Simple steps to equity in child survival. BMC Med. 2013;11:261. Medline:24344755 doi:10.1186/1741-7015-11-261

21 Afsana K, Haque MR, Sobhan S, Shahin SA. BRAC's Experience in scaling-up MNP in Bangladesh. Asia Pac J Clin Nutr. 2014;23:377-84. Medline:25164447

22 World Health Organization. Ending Preventable Child Deaths from Pneumonia and Diarrhea by 2025: The Integrated Global Action Plan for Pneumonia and Diarrhea (GAPPD). Geneva: World Health Organization; 2013.

23 Perry HB, King-Schultz L, Aftab A, Bryant J. Health equity issues at the local level: socio-geography, access, and health outcomes in the service area of the Hôpital Albert Schweitzer-Haiti. Int J Equity Health. 2007;6:7. Medline:17678540 doi:10.1186/1475-9276-6-7

24 Perry H, Rassekh B, Gupta S, Wilhelm J, Freeman P. A comprehensive review of the evidence regarding the effectiveness of community-based primary health care in improving maternal, neonatal and child health: 1. rationale, methods and database description. J Glob Health. 2017;7:010901.

25 Welch V, Tugwell P, Petticrew M, de Montigny J, Ueffing E, Kristjansson B, et al. How effects on health equity are assessed in systematic reviews of interventions. Cochrane Database Syst Rev. 2010;MR000028. Medline:21154402

26 Welch V, Petticrew M, Tugwell P, Moher D, O’Neill J, Waters E, et al. PRISMA-Equity 2012 extension: reporting guidelines for systematic reviews with a focus on health equity. PLoS Med. 2012;9:e1001333. Medline:23222917 doi:10.1371/ journal.pmed.1001333

27 Winestock-Luna J, Victora C. Considerations for Incorporating Health Equity into Project Designs: A Guide for Community-Oriented Maternal, Neonatal, and Child Health Projects. Washington, DC: USAID, 2011.

28 Gwatkin DR. 10 Best resources on...health equity. Health Policy Plan. 2007;22:348-51. Medline:17698890 doi:10.1093/ heapol/czm028

29 Bryce J, Victora CG, Boerma T, Peters DH, Black RE. Evaluating the scale-up for maternal and child survival: a common framework. Int Health. 2011;3:139-46. Medline:24038362 doi:10.1016/j.inhe.2011.04.003

30 Jennings MC, Pradhan S, Schleiff M, Sacks E, Freeman P, Gupta S. A comprehensive review of the evidence regarding the effectiveness of Community-based Primary Health Care in improving maternal, neonatal, and child health: 2.Maternal health Findings. J Glob Health. 2017;7:010902.

31 Sacks E, Freeman P, Jennings MC, Rassekh B, Gupta S, Perry H. A comprehensive review of the evidence regarding the effectiveness of Community-based Primary Health Care in improving maternal, neonatal, and child health: 3. neonatal health findings. J Glob Health. 2017;7:010903. 
32 Freeman P, Schleiff M, Sacks E, Rassekh B, Gupta S, Perry H. A comprehensive review of the evidence regarding the effectiveness of Community-based Primary Health Care in improving maternal, neonatal, and child health: 4 . child health findings. J Glob Health. 2017;7:010904.

33 Perry H, Rassekh B, Gupta S, Freeman P. A comprehensive review of the evidence regarding the effectiveness of community-based primary health care in improving maternal, neonatal and child health: 6 . strategies used by effective projects. J Glob Health. 2017;7:010906.

34 Tanser F, Gijsbertsen B, Herbst K. Modelling and understanding primary health care accessibility and utilization in rural South Africa: an exploration using a Geographical Information System. Soc Sci Med. 2006;63:691-705. Medline:16574290 doi:10.1016/j.socscimed.2006.01.015

35 Houweling TA, Tripathy P, Nair N, Rath S, Rath S, Gope R, et al. The equity impact of participatory women's groups to reduce neonatal mortality in India: secondary analysis of a cluster-randomised trial. Int J Epidemiol. 2013;42:520-32. Medline:23509239 doi:10.1093/ije/dyt012

36 Valdivia M. Public health infrastructure and equity in the utilization of outpatient health care services in Peru. Health Policy Plan. 2002;17 Suppl:12-9. Medline:12477737 doi:10.1093/heapol/17.suppl_1.12

37 Alberts JF, Sanderman R, Eimers JM, van den Heuvel WJ. Heuler Wvd. Socioeconomic inequity in health care: a study of services utilization in Curaçao. Soc Sci Med. 1997;45:213-20. Medline:9225409 doi:10.1016/S0277-9536(96)00338-3

38 Bohren MA, Vogel J, Hunter E, Lutsiv O, Makh S, Souza JP, et al. The mistreatment of women during childbirth in health facilities globally: a mixed-methods systematic review. PLoS Med. 2015;12:e1001847. Medline:26126110 doi:10.1371/ journal.pmed.1001847

39 Tappis H, Koblinsky M, Doocy S, Warren N, Peters D. Bypassing primary care facilities for childbirth: findngs from a multilevel analysis of skills birth attendance determinants in Afghanistan. J Midwifery Womens Health. 2016;61:18595. Medline:26861932 doi:10.1111/jmwh.12359

40 Ahmed S, Khan MM. Is demand-side financing equity enhancing? Lessons from a maternal health voucher scheme in Bangladesh. Soc Sci Med. 2011;72:1704-10. Medline:21546145 doi:10.1016/j.socscimed.2011.03.031

41 Baqui AH, Rosecrans AM, Williams EK, Agarwal PK, Ahmed S, Darmstadt G. NGO facilitation of a government community-based maternal and neonatal health programme in rural India: improvements in equity. Health Policy Plan. 2008;23:234-43. Medline:18562458 doi:10.1093/heapol/czn012

42 Kumar V, Kumar A, Das V, Srivastava N, Baqui A, Darmstadt G. Community-driven impact of a newborn-focused behavioral intervention on maternal Health in Shivarg, India. Int J Gynaecol Obstet. 2012;117:48-55. Medline:22281244 doi:10.1016/j.ijgo.2011.10.031

43 World Bank. Analyzing Health Equity: Introduction. 2008. Available: https://openknowledge.worldbank.org/handle/10986/6896. Accessed: 26 April 2017.

44 Chopra M, Sharkey A, Dalmiya N, Anthony D, Birkin N. Strategies to improve health coverage and narrow the equity gap in child survival, health, and nutrition. Lancet. 2012;380:1331-40. Medline:22999430 doi:10.1016/S01406736(12)61423-8

45 Winestock Luna J, Monga T, Morgan L. Equity matters-lessons from MCHIP and CSHGP in Measuring and Improving Equity. Washington, DC: USAID/MCHIP, 2014.

46 Anderson LM, Adeney K, Shinn C, Safranek S, Buckner-Brown J, Krause LK. Community coalition-driven interventions to reduce health disparities among racial and ethnic minority populations. Cochrane Database Syst Rev. 2015;6:CD009905. Medline:26075988

47 Scheil-Adlung X. Global evidence on inequities in rural health protection: new data on rural deficits in health coverage for 174 countries. Extension of Social Security. 2015. Available: http://www.social-protection.org/gimi/gess/RessourcePDF.action?ressource.ressourceId=51297. Accessed: 26 April 2017.

48 Lassi Z, Kumar R, Bhutta Z. Community-based Care to Improve Maternal, Newborn, and Child Health. In: Black R, Laxminarayan R, Temmerman M, walker N, editors. Reproductive, Maternal, Newborn, and Child Health. 3rd ed. Washington DC; World Bank Group: 2016.

49 Ikeda N, Saito E, Kondo N, Inoue M, Ikeda S, Satoh T, et al. What has made the population of Japan Healthy? Lancet. 2011;378:1094-105. Medline:21885105 doi:10.1016/S0140-6736(11)61055-6

50 Rifkin SB. A framework linking community empowerment and health equity: it is a matter of CHOICE. J Health Popul Nutr. 2003;21:168-80. Medline:14717563

51 Victora CG, Wagstaff A, Schellenberg JA, Gwatkin D, Claeson M, Habicht J-P. Applying an equity lens to child health and mortality: more of the same is not enough. Lancet. 2003;362:233-41. Medline:12885488 doi:10.1016/S01406736(03)13917-7

52 Szwarcwald CL, Souza-Junior PR, Damacena GN. Socioeconomic inequalities in the use of outpatient services in Brazil according to health care need: evidence from the World Health Survey. BMC Health Serv Res. 2010;10:217. Medline:20653970 doi:10.1186/1472-6963-10-217

53 Malik SM, Ashraf N. Equity in the use of public services for mother and newborn child health care in Pakistan: a utilization incidence analysis. Int J Equity Health. 2016;15:120. Medline:27459961 doi:10.1186/s12939-016-0405-x 